\title{
THE VISIBLE AND ULTRAVIOLET ABSORPTION SPECTRA OF CAROTIN AND XANTHOPHYLL AND THE CHANGES ACCOMPANYING OXIDATION
}

\author{
By H. J. McNicholas
}

\section{ABSTRACT}

The absorption spectra of equal molecular concentrations of pure carotin and xanthophyll in alcohol-ether solution are studied throughout the visible and ultraviolet spectral range, and the changes in these spectra are followed as the pigments oxidize slowly in solution.

The frequencies of the absorption bands for each pure unoxidized pigment appear to form a regular sequence extending throughout the observed spectral range and converging toward the lower frequencies in accordance with a simple parabolic law for each pigment. The imposition of a periodic variation in intensity on this progression of bands gives the appearance of three adjacent spectral regions of selective absorption which are partially resolved into overlapping component bands.

During oxidation of the pigments both spectra pass through the same characteristic series of changes, which are such as to indicate two very definite stages in the oxidation process for each pigment. Carotin is not oxidized to xanthophyll in this process, as contended by some previous investigators. The stages of oxidation are closely related to the two stages of hydrogenation described by Zechmeister and his associates. The oxidation data confirm the contentions of Schertz and others that the different xanthophylls described by Tswett may represent distinct stages in the oxidation of a single pigment.

\section{CONTENTS}

I. Introduction

II. Methods and nomenclature

III. Preparation and exposure of the solutions....... 174

1. Choice of solvent.

2. Experimental procedure

IV. Absorption spectra of the pure pigments

V. Oxidation in solution

1. Experimental data. 185

2. Test for oxidation 188

VI. Bearing of the oxidation experiments on the work of other investigators

\section{INTRODUCTION}

The wide distribution of the chloroplast pigments ${ }^{1}$ in the tissues of plants and animals has attracted the attention of biologists since earliest times. Much progress has been made in the isolation,

1 The chloroplast pigments constitute a group of four pigments which are always found closely associated in the chloroplastids of plant cells. These pigments are carotin, xanthophyll, chlorophyll- $a$, and chlorophyll- $b$. Other closely related pigments such as lycopin (an isomer of carotin), fucoxanthin, and some chlorophyll derivatives, are also found under certain conditions in the plastids of various plant cells. 
identification, and classification of these pigments, but our knowledge of their significance, relationship, or function, in the metabolism of plant and animal life, has hardly progressed beyond the realms of speculation. A comprehensive discussion of the subject is contained in the books by Willstatter and Stoll, ${ }^{2}$ Palmer, ${ }^{3}$ and Spoehr. ${ }^{4}$

Carotin and xanthophyll are the two yellow chloroplast pigments occurring in relatively large quantities along with chlorophyll in green plants. Carotin is a highly unsaturated hydrocarbon, $\mathrm{C}_{40} \mathrm{H}_{56}$, and one of the few naturally occurring "colored" hydrocarbons. Xanthophyll is very similar to carotin in its physical and chemical properties, and has the atomic composition $\mathrm{C}_{40} \mathrm{H}_{56} \mathrm{O}_{2}$. The molecular structure of these pigments is not definitely determined. Their isolation and the study of their physical and chemical properties is fraught with many difficulties, owing, in part, to the ease with which the pigments take up oxygen, either in solution or in the solid state. Some of their most characteristic properties undergo a marked alteration even in the earliest stage of oxidation. This is true of the spectral absorptive properties, which have long been a valuable aid in the identification and quantitative estimation of the pigments.

Many attempts have been made by various investigators to explain the presence and mysterious associations of these yellow pigments. Thus, the close correlation between carotin pigmentation and vitamin A content of plant tissues and the presence of carotin in milk and xanthophyll in egg yolks has led to much controversial discussion of the probable significance of these associations. Hypothetical relationships between the chloroplast pigments and theories of the interconversion of these pigments in the process of photosynthesis have all been advanced from time to time. Usually these speculations have not been substantiated by careful and thorough experimentation. From the standpoint of molecular structure and possible function in the living plant the great affinity of carotin and xanthophyll for oxygen is a matter of considerable interest. It has been contended that these pigments may play a respiratory rôle or aid in the regulation of oxygen pressure in the plant cells.

Aside from the academic and biological interest which may be attached to a study of the absorptive properties of the chloroplast pigments, the information thereby obtained is of value in the manufacture, purification, and bleaching of regetable oils and other natural food products, such as flour, the color of which is a matter of considerable commercial importance. It is known that carotin, xanthophyll, and chlorophyll or its derivatives, are present in varying proportions in these materials and often play the chief rôle in determining the color of the finished product.

In the course of some studies of the chloroplast pigments, conducted at the Bureau of Plant Industry, United States Department of Agriculture, preparations of pure carotin and xanthophyll were made by Dr. F. M. Schertz, who also studied some of the physical and chemical properties ${ }^{5}$ of these materials and applied colorimetric and spectrophotometric methods in their quantitative estimation. ${ }^{6}$ Through

2 Investigations on Chlorophyll. Authorized English translation from the German by F. M. Schertz and A. R. Merz. Published by F. M. Schertz, 1305 Farragut Street, NW., Washington, D. C.

Carotinoids and Related Pigments. The Chemical Catalogue Co. (Inc.); 1922.

- Photosynthesis. The Chemical Catalogue Co. (lnc.); 1926.

8 J. Agri. Research, 30, p. 469; 1925 (carotin), 30, 575; 1925 (xanthophyll).

- J. Agri. Research, 26, p. 383; 1923 (carotin), 30, 253; 1925 (xanthophyll). 
the generosity of Doctor Schertz, freshly prepared crystals of pure carotin and xanthophyll were obtained for the present investigation. The author wishes to acknowledge his indebtedness to Doctor Schertz for his whole-hearted interest and assistance in the work and for his painstaking efforts to supply materials of the highest possible purity.

In the present investigation the absorption spectra of pure carotin and xanthophyll are studied throughout the visible and ultra-violet spectral range, and the changes in these spectra are followed as the pigments oxidize slowly in solution. The oxidation data afford the principle subject for discussion, inasmuch as they have an important bearing on some experimental results and conclusions of other investigators. The structure of the absorption spectrum of each pure unoxidized pigment is fully described, but a detailed discussion of the significance of this structure, or its implications regarding possible structural relations of carotin and xanthophyll to other chloroplast pigments, must await the further development of absorption theory and the completion of much more experimental work on these materials.

\section{METHODS AND NOMENCLATURE}

Detailed descriptions of the methods and apparatus used in the present investigation have been given in other publications. The visual method, ${ }^{7}$ using the Koenig-Martens spectrophotometer, ${ }^{8}$ and the photoelectric method ${ }^{9}$ have been used to supplement and extend the photographic method ${ }^{10}$ in the visible spectrum. All measurements in the ultra-violet were made by the photographic method, in which the underwater spark is used with a Hilger sector photometer and quartz spectrograph.

In each of these methods the transmission of a cell containing the solution is compared at different spectral frequencies (or wave lengths) with the transmission of a duplicate cell containing the solvent. If the transmissions of the cells containing the solution and solvent are represented by $T_{s o i}$ and $T_{s o v}$, respectively, the absorbancy ${ }^{11}$ is then defined by the following relation,

$$
\text { Absorbancy } \equiv-\log _{10} \frac{T_{s o l}}{T_{\text {sov }}}=b c \mathbf{k}
$$

wherein $b$ is the thickness of the absorbing layer, $c$ is the concentration of the absorber, and $\mathbf{k}$ is the specific absorptive index. The latter quantity is a function of the frequency (or wave length) and is a characteristic property of the absorber and its immediate environment. The environmental effects of usual interest in these measurements are determined by the temperature, the nature of the solvent, and the concentration of the absorber. The temperature coefficient of change is usually small, and in the present investigation measurements were made at ordinary room temperatures without specific con-

7 MeNicholas, B. S. Jour. Research, 1, p. 793; 1928.

8 Martens and Grünbaum, Ann. der Phys. (4), 12, p. 984; 1903.

9 Gibson, J. Opt. Soc. and Rev. Sci. Inst., 7, p. 693; 1923.

10 Howe, Phys. Rev. (2), 8, p. 674; 1916. B. S. Sci. Papers (No. 440), 18, p. 121; 1922: B. S. Jour. Research, 1, p. 939; 1928 .

11 For previous use of this term see R. Davis and K. S. Gibson, Filters for the Reproduction of Sunlight and Daylight and the Determination of Color Temperature. B. S. Miscellaneous Publication, No. 114, p. 39. 
trol. Likewise, for the range of relatively low concentrations covered, the specific absorptive index may be considered independent of the concentration, so that, for a given solvent, the absorbancy is simply proportional to the product $b c$. This condition is generally expressed as Beer's law of absorption.

In the present work a convenient molecular concentration is chosen arbitrarily as the unit. This unit, for carotin, is $0.80 \mathrm{cg}$ of the pure pigment in 1 liter of the solution. The same (unit) molecular concentration of xanthophyll, then, is $0.85 \mathrm{cg}$ of the pigment in 1 liter of the solution. The pure crystals were known to contain no solvent molecules of crystalization. Taking the unit of thickness as the centimeter, measurements were made for values of the product $b c$ equal to 1,5 , and 10 . In the graphical presentation of the absorption spectra (figs. 1, 2, 4, and 5) the absorbancy for the above given values of $b c$ is shown as a function of the frequency with the unit of frequency chosen as one vibration cycle per micro-micro-second $\left(10^{-12}\right.$ sec.). Hence

$$
\text { Frequency }=\frac{\text { Vibrations }}{\text { sec. } \times 10^{12}}=\frac{3 \times 10^{5}}{\text { Wave length in millimicrons }}
$$

\section{PREPARATION AND EXPOSURE OF THE SOLUTIONS}

\section{CHOICE OF SOLVENT}

In order to extend the absorption measurements as far as possible into the ultra-violet it is of importance to consider the absorptive properties of the organic solvents available for carotin and xanthophyll. As shown by Brode ${ }^{12}$ the majority of these solvents, such as carbon disulphide, acetone, benzene, carbon tetrachloride, chloroform, and petroleum ether, exhibit strong general absorption in the far ultraviolet and are for this reason unsuited for the present work. Pure ethyl alcohol and ethyl ether, on the other hand, are quite transparent up to frequencies of 1,250 or 1,300 , and were therefore selected for this investigation.

Different samples of alcohol or ether, however, may differ widely in their absorptive properties in the far ultra-violet, because of impurities which are usually present in small amounts, but which may exhibit, nevertheless, very strong selective or general absorption in this region. It is known that oxidation products may gradually form in alcohol and ether. Other impurities, such as benzene, may be present when this substance is used to dehydrate the alcohol. Although these impurities may be of no consequence in the usual chemical applications of these solvents, they are obviously of considerable importance in the absorption measurements. It is necessary to work with carefully purified or freshly distilled materials, free from sharp absorption bands or strong general absorption, and always to use the same batch of solvent in the solvent cell as used in the preparation of the solution.

It has been shown by Clover ${ }^{13}$ that when a glass-stoppered bottle of ethyl ether is allowed to stand for several months, it acquires oxidizing properties which may be attributed to the formation of 
ethyl peroxide. This oxidation of the ether is accelerated by the action of light. The experiments of Schertz ${ }^{14}$ have shown that both carotin and xanthophyll oxidize quite readily in pure, freshly distilled ethyl ether, but are comparatively stable in petroleum ether and alcohol solutions. It is probable that the formation of the peroxide in ethyl ether is responsible for the more rapid oxidation of the pigments in this solvent.

It seemed desirable to use ether as a solvent for the oxidation experiments. The pigments are also more soluble in ether than in alcohol. The high volatility of ether, however, introduced some difficulties in the absorption measurements, because of the occasional leakage of the ether from the particular type of absorption cell used in this work. ${ }^{15}$ To meet in the most satisfactory manner these and other conditions arising in the preparation, measurement, and exposure of the solutions, the pigments were exposed to oxidation agencies in a fairly concentrated solution containing a high percentage of ether, and the solution then diluted with alcohol for the absorption measurements. All of the alcohol and ether used was previously redistilled and tested for the presence of any unusual absorption in the far ultra-violet. Sufficient volumes of each of these solvents were then set aside to supply all needs in the work.

\section{EXPERIMENTAL PROCEDURE}

The work on carotin was undertaken first. Having determined by preliminary trials the concentrations most suitable for the measurements, $2.00 \mathrm{cg}$ of the freshly prepared crystals were weighed at the Bureau of Plant Industry and immediately transported to the $\mathrm{Na}$ tional Bureau of Standards under a little absolute ethyl alcohol, sufficient to completely cover the crystals and thus to prevent undue exposure to oxidizing agencies. At the National Bureau of Standards the alcohol was increased to $50 \mathrm{ml}$ and sufficient absolute ethyl ether was added to dissolve the crystals completely and to make up exactly $250 \mathrm{ml}$ at the proper temperature, as designated for the graduation mark on the flask. The result was a stock solution of carotin, with a molecular concentration of 10 units, in a solvent consisting of 20 per cent alcohol and 80 per cent ether.

The preparation of the crystals and the solution occupied the greater part of one day. The solution was then stored in a cool, dark place and absorption measurements made on the following day. For these measurements the following dilutions were made:

Solution No. 1.-To $10 \mathrm{ml}$ of the stock solution $30 \mathrm{ml}$ of alcohol was added making a concentration of 2.5 molecular units in a solvent consisting of 80 per cent alcohol and 20 per cent ether. This solution was used in thicknesses of 2 and $4 \mathrm{~cm}$ ( $b c=5$ and 10 , respectively) for measurements in the ultra-violet region of the spectrum.

Solution No. 2.-To $10 \mathrm{ml}$ of solution No. 1, $40 \mathrm{ml}$ of a mixture of 80 per cent alcohol and 20 per cent ether was added, making a molecular concentration of 0.5 unit in a solvent consisting, as before, of

\footnotetext{
$14 \mathrm{~J}$. Agr. Research, 30, pp. 469, 575; 1925.

15 The construction of the cell is described in B. S. Sci. Paper No. 440. (See footnote 10.) The giass end plates are replaced by quartz plates for the ultra-violet measurements. These plates are clamped tightly against the finely ground plane-parallel ends of a glass tube. If the plates and ends of the tube do not make exceptionally good contact, highly volatile solvents, such as ether, will gradually leak out.
} 
80 per cent alcohol and 20 per cent ether. This solution was used in a thickness of $2 \mathrm{~cm}(b c=1)$ for measurements in the visible and near ultra-violet.

All data obtained on the pure pigment in solution are given in Figure 1, and are discussed later in Section IV.

After solutions Nos. 1 and 2 were prepared, the stock solution, contained in a tightly-stoppered colorless-glass bottle, was placed on a shelf near a south window of the laboratory. The solution was thus exposed to diffused light from the walls of the room and to direct light from the southern sky, after transmission by the window glass and glass wall of the container. No direct sunlight was at any time incident on the solution. Two colorless-glass bottles, containing, respectively, pure alcohol and the $80: 20$ alcohol-ether mixture, were exposed with the stock solution to the same conditions of temperature and illumination. These bottles held sufficient volumes of the two solvents to supply all needs in future dilutions of the stock solution and for use in the solvent cell. No record was kept of weather conditions during the period of exposure. ${ }^{16}$ The absorption spectrum of the slowly oxidizing material was redetermined at intervals of four or five weeks, the same experimental procedure being followed in each redetermination as described above for the pure pigment. The resulting absorption curves, with the record of exposure times, are shown in Figure 4 and are discussed in Section V.

The solution of xanthophyll was prepared and the absorption measurements begun approximately four months after the first measurement had been made on carotin. The procedure in making the solution and in carrying out the measurements was the same as that just described for carotin. The results are shown in Figures 2 and 5 and are discussed in Sections IV and V.

In order to work with molecular concentrations of xanthophyll, equal to the concentrations previously chosen for carotin, $2.12 \mathrm{cg}$ of the freshly prepared crystals were weighed and dissolved in the alcohol-ether solvent. Different stocks of alcohol and ether were used for this series of measurements, but were selected, as before, with due regard to ultra-violet transparency. The stock solution was exposed at the same location in the laboratory, but the exposure periods were not simultaneous with those of carotin, of course, being made during different months of the year. (See legends of figs. 4 and 5.) The rates of oxidation of the two pigments are, therefore, not strictly comparable.

\section{ABSORPTION SPECTRA OF THE PURE PIGMENTS}

The visible and ultra-violet absorption spectra of pure carotin and xanthophyll in equal molecular concentrations are shown in Figures 1 and 2. Values of absorbancy, as read from the curves, are also listed in Table 1.

In the early studies of these absorption spectra the various investigators recorded only two or three bands for each pigment, and sometimes a fourth band for xanthophyll. These bands are the definitely resolved components of the strong group of bands in the blue and violet regions of the visible spectrum. All the early work was done by

16 These records are obtainable from the U.S. Weather Bureau. See dates of exposure in legends to Figures 4 and 5. 


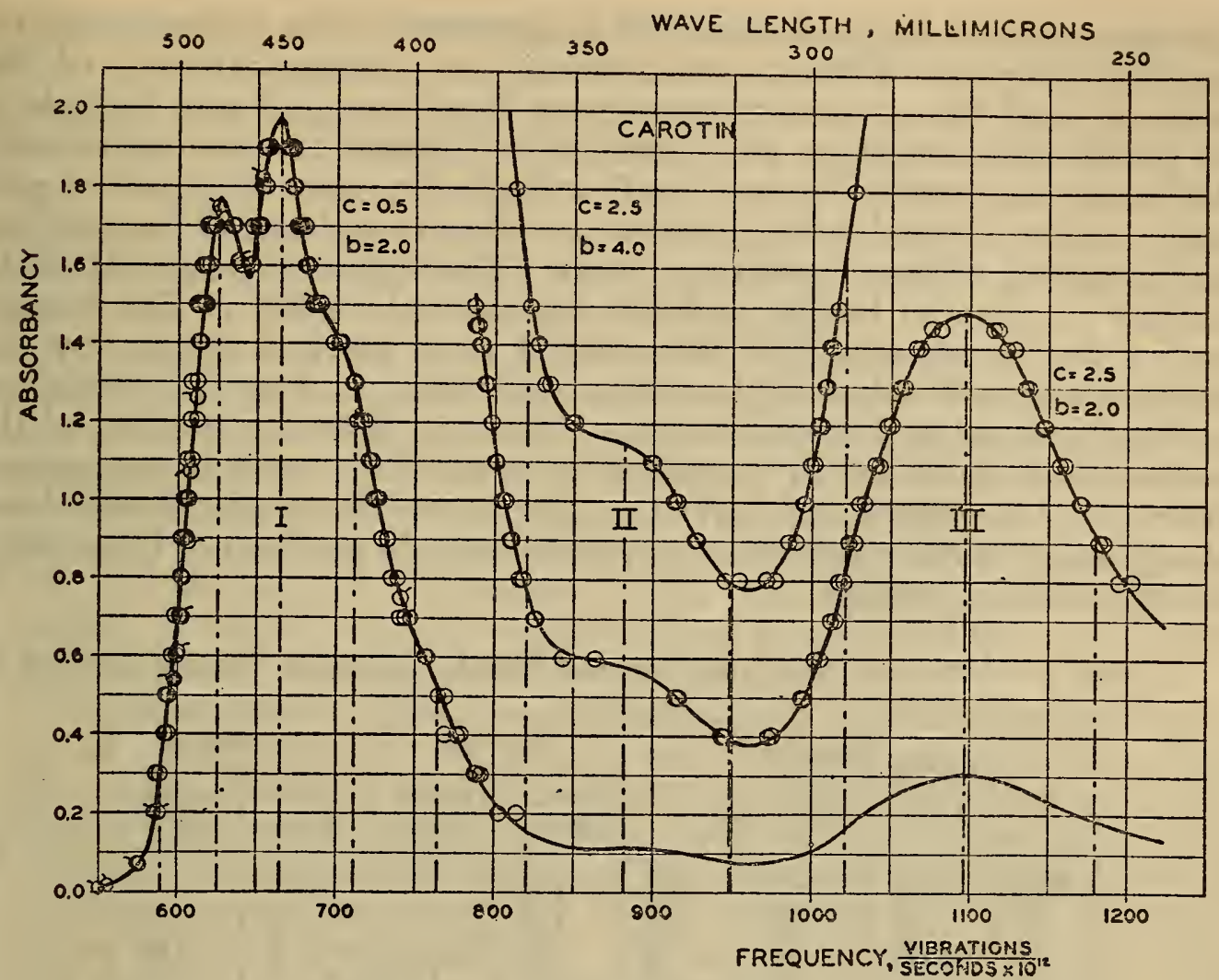

FIGURE 1.-Visible and ultra-violet absorption spectrum of carotin

Solvent: 80 per cent alcohol +20 per cent ether. Unit concentration (c) is $0.80 \mathrm{cg} / 1$; unit thickness $(b)$ is $1 \mathrm{~cm}$. Methods: Open circles, photographic; hooked circles, visual.

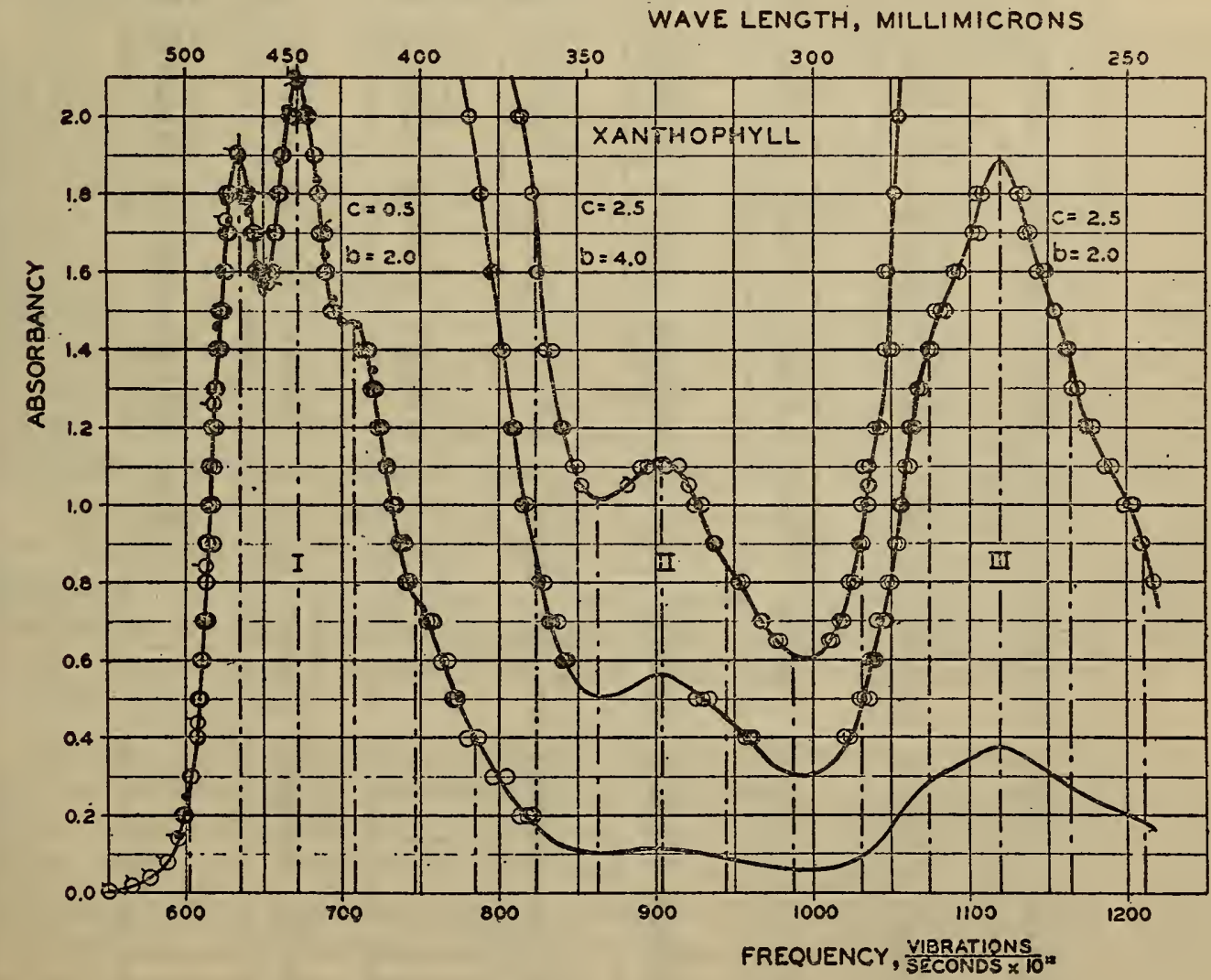

FIGURE 2.-Visible and ultra-violet absorption spectrum of xanthophyll

Solvent: 80 per cent alcohol +20 per cent ether. Unit concentration $(c)$ is $0.85 \mathrm{cg} / 1$; unit thickness $(b)$ is $1 \mathrm{~cm}$. Methods: Open circles, photographic; hooked circles, visual; filled circles, photo-electric. 
the spectrogram method, in which a spectrum of the source is photographed through different thicknesses (or concentrations) of the solution, and the several spectrograms then arranged side by side in an order corresponding to increasing thickness (or concentration). Although this method serves well enough for some qualitative purposes, it is not suitable for quantitative determinations of the position and intensity of the absorption bands. The apparent positions of the centers or edges of bands, and the relative intensities of the weaker and wider bands, may be determined to a marked degree by the spectral characteristics of the source and plate, and by the procedure in development and reproduction. Although these limitations of the method have been fully recognized by some of the early investigators, others, on the other hand, have been led to erroneous conclusions from observations of the position or apparent shift in position of the centers or edges of the bands.

TABLE 1.-Values of absorbancy as read from the curves in Figures 1 and 2

\begin{tabular}{|c|c|c|c|c|c|c|c|}
\hline \multirow[b]{2}{*}{$\nu$} & \multirow{2}{*}{$\begin{array}{c}\text { Carotin } \\
c=0.5 \\
b=2.0\end{array}$} & \multirow{2}{*}{$\begin{array}{c}\text { Xantho- } \\
\text { phyll } \\
c=0.5 \\
b=2.0\end{array}$} & \multirow[b]{2}{*}{$\nu$} & \multicolumn{2}{|c|}{ Carotin } & \multicolumn{2}{|c|}{ Xanthophyll } \\
\hline & & & & $\begin{array}{l}c=2.5 \\
b=2.0\end{array}$ & $\begin{array}{l}c=2.5 \\
b=4.0\end{array}$ & $\begin{array}{l}c=2.5 \\
b=2.0\end{array}$ & $\begin{array}{l}c=2.5 \\
b=4.0\end{array}$ \\
\hline $\begin{array}{r}5.50 \\
60 \\
70 \\
80 \\
90\end{array}$ & $\begin{array}{r}0.01 \\
.02 \\
.04 \\
.09 \\
.35\end{array}$ & $\begin{array}{l}0.00 \\
.01 \\
.02 \\
.05 \\
.09\end{array}$ & $\begin{array}{r}780 \\
790 \\
800 \\
10 \\
20\end{array}$ & $\begin{array}{r}1.45 \\
1.14 \\
.93 \\
.78\end{array}$ & 1.59 & $\begin{array}{l}2.04 \\
1.77 \\
1.48 \\
1.19 \\
.94\end{array}$ & $\begin{array}{l}2.08 \\
1.88\end{array}$ \\
\hline $\begin{array}{r}600 \\
05 \\
10 \\
15 \\
20\end{array}$ & $\begin{array}{r}.68 \\
.95 \\
1.21 \\
1.50 \\
1.68\end{array}$ & $\begin{array}{r}.22 \\
.32 \\
.55 \\
.99 \\
1.34\end{array}$ & $\begin{array}{l}30 \\
40 \\
50 \\
60 \\
70\end{array}$ & $\begin{array}{l}.67 \\
.62 \\
.60 \\
.60 \\
.59\end{array}$ & $\begin{array}{l}1.35 \\
1.24 \\
1.20 \\
1.18 \\
1.16\end{array}$ & $\begin{array}{l}.74 \\
.61 \\
.54 \\
.51 \\
.51\end{array}$ & $\begin{array}{l}1.44 \\
1.21 \\
1.07 \\
1.02 \\
1.02\end{array}$ \\
\hline $\begin{array}{l}25 \\
30 \\
35 \\
40 \\
45\end{array}$ & $\begin{array}{l}1.76 \\
1.74 \\
1.68 \\
1.60 \\
1.57\end{array}$ & $\begin{array}{l}1.60 \\
1.83 \\
1.90 \\
1.83 \\
1.64\end{array}$ & $\begin{array}{r}80 \\
90 \\
900 \\
10 \\
20\end{array}$ & $\begin{array}{l}.58 \\
.57 \\
.55 \\
.52 \\
.48\end{array}$ & $\begin{array}{r}1.15 \\
1.13 \\
1.10 \\
1.04 \\
.96\end{array}$ & $\begin{array}{l}.52 \\
.54 \\
.56 \\
.55 \\
.53\end{array}$ & $\begin{array}{l}1.04 \\
1.08 \\
1.12 \\
1.10 \\
1.06\end{array}$ \\
\hline $\begin{array}{l}50 \\
55 \\
60 \\
65 \\
70\end{array}$ & $\begin{array}{l}1.71 \\
1.86 \\
1.94 \\
1.98 \\
1.90\end{array}$ & $\begin{array}{l}1.54 \\
1.62 \\
1.79 \\
1.96 \\
2.09\end{array}$ & $\begin{array}{l}30 \\
40 \\
50 \\
60 \\
70\end{array}$ & $\begin{array}{l}.44 \\
.42 \\
.39 \\
.38 \\
.38\end{array}$ & $\begin{array}{l}.89 \\
.83 \\
.79 \\
.78 \\
.79\end{array}$ & $\begin{array}{l}.50 \\
.47 \\
.43 \\
.39 \\
.34\end{array}$ & $\begin{array}{l}.96 \\
.88 \\
.82 \\
.76 \\
.68\end{array}$ \\
\hline $\begin{array}{l}75 \\
80 \\
85 \\
90 \\
95\end{array}$ & $\begin{array}{l}1.75 \\
1.63 \\
1.54 \\
1.49 \\
1.45\end{array}$ & $\begin{array}{l}2.07 \\
1.96 \\
1.80 \\
1.59 \\
1.50\end{array}$ & $\begin{array}{r}80 \\
90 \\
1,000 \\
10 \\
20\end{array}$ & $\begin{array}{l}.41 \\
.46 \\
.55 \\
.65 \\
.81\end{array}$ & $\begin{array}{r}.84 \\
.92 \\
1.09 \\
1.32 \\
1.62\end{array}$ & $\begin{array}{l}.32 \\
.30 \\
.30 \\
.32 \\
.37\end{array}$ & $\begin{array}{l}.64 \\
.61 \\
.60 \\
.64 \\
.73\end{array}$ \\
\hline $\begin{array}{r}700 \\
05 \\
10 \\
15 \\
20\end{array}$ & $\begin{array}{l}1.41 \\
1.37 \\
1.31 \\
1.23 \\
1.13\end{array}$ & $\begin{array}{l}1.47 \\
1.47 \\
1.47 \\
1.40 \\
1.29\end{array}$ & $\begin{array}{l}30 \\
40 \\
50 \\
60 \\
70\end{array}$ & $\begin{array}{l}.97 \\
1.09 \\
1.21 \\
1.33 \\
1.42\end{array}$ & & $\begin{array}{r}.47 \\
.64 \\
.81 \\
1.12 \\
1.35\end{array}$ & $\begin{array}{l}.91 \\
1.17 \\
1.63\end{array}$ \\
\hline $\begin{array}{l}25 \\
30 \\
35 \\
40 \\
45\end{array}$ & $\begin{array}{r}1.01 \\
.92 \\
.82 \\
.76 \\
.70\end{array}$ & $\begin{array}{l}1.17 \\
1.04 \\
.92 \\
.83 \\
.77\end{array}$ & $\begin{array}{r}80 \\
90 \\
1,100 \\
10 \\
20\end{array}$ & $\begin{array}{l}1.46 \\
1.48 \\
1.49 \\
1.47 \\
1.43\end{array}$ & & $\begin{array}{l}1.49 \\
1.58 \\
1.69 \\
1.83 \\
1.89\end{array}$ & \\
\hline $\begin{array}{l}50 \\
55 \\
60 \\
65 \\
70\end{array}$ & $\begin{array}{l}.65 \\
.61 \\
.56 \\
.52 \\
.47\end{array}$ & $\begin{array}{l}.74 \\
.71 \\
.64 \\
.58 \\
.53\end{array}$ & $\begin{array}{l}30 \\
40 \\
50 \\
60 \\
70\end{array}$ & $\begin{array}{r}1.36 \\
1.27 \\
1.17 \\
1.08 \\
.99\end{array}$ & & $\begin{array}{l}1.81 \\
1.66 \\
1.54 \\
1.43 \\
1.27\end{array}$ & \\
\hline $\begin{array}{r}80 \\
90 \\
800 \\
10 \\
20\end{array}$ & $\begin{array}{l}.37 \\
.29 \\
.23 \\
.19 \\
.16\end{array}$ & $\begin{array}{l}.44 \\
.37 \\
.30 \\
.24 \\
.19\end{array}$ & $\begin{array}{r}80 \\
90 \\
1,200 \\
10 \\
20\end{array}$ & $\begin{array}{l}.92 \\
.85 \\
.79 \\
.74 \\
.70\end{array}$ & $\begin{array}{l}-. \\
-- \\
--\end{array}$ & $\begin{array}{l}1.17 \\
1.09 \\
1.01 \\
.91 \\
.75\end{array}$ & \\
\hline
\end{tabular}


Quantitative spectrophotometric observations of the visible and ultra-violet absorption spectra of carotin in cyclohexane and of xanthophyll in methanol have been recorded recently by Pummerer, Rebmann, and Reindel. ${ }^{17}$ The data show the general similarity in form of the absorption curves for these pigments, but the observations are not sufficiently extensive and the curves not determined with sufficient precision to reveal some structural details of the spectra which will be described on the following pages.

A comparison of the absorption curves in Figures 1 and 2 shows only minor differences in the structure of the spectra. The mean absorbancy of the equimolecular solutions, when averaged over the frequency range from 550 to 850 (for $b c=1$ ) is 0.82 for both carotin and xanthophyll. When averaged over the frequency range from 850 to 1,220 (for $b c=5$ ) the mean absorbancy is 0.86 for carotin and 0.88 for xanthophyll. Compared with carotin the spectrum of xanthophyll is shifted slightly to the higher frequencies and the component bands are sharper and closer together.

This sharpness of bands of xanthophyll is of particular interest in that it clearly reveals the overlapping component structure of the strong band group in the visible spectrum. Four components of this group are distinctly observed; a fifth component near frequency 602 is indicated by a slight indentation in the absorption curve, and another component near frequency 823 is also suggested by the curves for greater values of the product $b c$. On inspection of the far ultra-violet band the same evidence for a component structure is observed. Even the weaker ultra-violet band at frequency 903, which is further developed during the oxidation process (fig. 5), shows definite evidence of components near frequencies 945 and 987 , respectively.

For carotin the structure is not so evident; but in view of the similarity in atomic composition and various properties of these pigments, and the sameness in form of their absorption curves, there can be little doubt that the same general scheme underlies the finer structure of their absorption spectra. Five components of the strong band group in the visible spectrum are observed. The far ultra-violet band shows evidence of a component structure by the definite indentations of the curve in the neighborhood of frequency 1021. Again, in the partially oxidized material (fig. 4), there is definite evidence of a band near frequency 949 . Compared with the spectrum of xanthophyll, however, the component bands of carotin, although somewhat farther apart, are broader and, consequently, less definitely resolved.

The observed absorption spectra of carotin and xanthophyll may be described as consisting each of three adjoining groups of overlapping component bands. These band groups will be designated hereafter by the Roman numerals I, II, and III, respectively, beginning with the strongest and most definitely resolved group in the visible spectrum.

As the band groups are not all clearly resolved, and the exact form of the overlapping components is unknown, one can not determine how closely the maximum ordinate of a band group coincides in position with the maximum ordinate of a component of that group. Although the positions of these maxima may be in themselves of little theoretical significance, they afford, nevertheless, the only definite 
means for locating the bands in the spectrum. In the further description and discussion of these spectra it will be assumed that the maximum ordinates of the different band groups give the true relative positions of the strongest components of these groups. These maximum ordinates are taken, furthermore, to define the positions of the groups in the spectrum.

It is observed that the band groups of xanthophyll are not equally spaced, but the separation of Groups I and II is from 15 to 16 frequency units greater than the separation of Groups II and III. With the exception of the two sharp components of Group I, which are separated by approximately 36 frequency units, any assignment of frequency differences between adjacent components of the group must necessarily be highly conjectural. One can not determine precisely whether they are equally spaced in each group or whether they form a slightly converging sequence. The spacing of the components in Group III is definitely greater than the spacing in Group I. The band groups of carotin appear equally spaced and separated by the same frequency interval (216 units) as observed between Groups II and III of xanthophyll. The spacing of the two definitely resolved components of Group I is approximately 41 frequency units.

A close inspection of the absorption curves suggests the possibility that the entire observed spectrum of each pigment might be represented as a single regular sequence of component bands converging toward the lower frequencies. Then, the imposition of a periodic variation in intensity on the progression of component bands gives rise to the appearance of definite band groups in the spectrum and the characteristic form of the absorption curves.

It is found that the observed progression of bands, for each pigment, is, indeed, well represented by the parabolic equation

$$
\nu-\nu_{o}=a\left(n-n_{o}\right)^{2}
$$

wherein $\nu_{o}, n_{o}$, and $a$ are constants determined from the experimental data and the required frequencies $\nu$ are given by successive integral values of $n$. The axis of this parabola is parallel to the axis of frequencies and the coordinates of the vertex are $\nu_{0}$ and $n_{0}$. In the evaluation of the constants of equation (1) only the frequencies of the maximum ordinates of the three band groups were used. The absolute integral values of $n$ are arbitrary, but relative values for the three band groups are determined definitely by the form of the absorption curves, which indicate how many component bands must be arranged in regular sequence, including the strongest components of each group. In this manner the following equations were obtained, in which the vertex of the parabola is placed at $n_{o}=-1 / 2$ :

Carotin: $n=6,7,8$, etc.

$\nu-480.2=2.57142(n+1 / 2)^{2}$

Xanthophyll: $n=40,41,42$, etc.

$\nu+93.0=0.42353(n+1 / 2)^{2}$ 
TABLE 2.-Calculated frequeacies of the absorption bands

\begin{tabular}{|c|c|c|c|}
\hline \multicolumn{2}{|c|}{$\begin{array}{c}\text { Carotin (by equa- } \\
\text { tion (2)) }\end{array}$} & \multicolumn{2}{|c|}{$\begin{array}{c}\text { Xanthophyll (by } \\
\text { equation (3)) }\end{array}$} \\
\hline$n$ & $\nu$ & $n$ & $\nu$ \\
\hline $\begin{array}{r}6 \\
7 \\
8 \\
9 \\
10 \\
11\end{array}$ & $\begin{array}{r}589 \\
625 \\
666 \\
712 \\
764 \\
+820\end{array}$ & $\begin{array}{l}40 \\
41 \\
42 \\
43 \\
44 \\
45\end{array}$ & $\begin{array}{r}602 \\
636 \\
672 \\
708 \\
746 \\
1784\end{array}$ \\
\hline $\begin{array}{l}12 \\
13 \\
14 \\
15 \\
16\end{array}$ & $\begin{array}{r}882 \\
949 \\
1,021 \\
1,098 \\
11,180\end{array}$ & $\begin{array}{l}46 \\
47 \\
48 \\
49 \\
50\end{array}$ & $\begin{array}{r}823 \\
1863 \\
903 \\
945 \\
987\end{array}$ \\
\hline 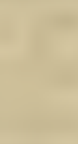 & & $\begin{array}{l}51 \\
52 \\
53 \\
54 \\
55\end{array}$ & $\begin{array}{l}1,030 \\
1,074 \\
1,119 \\
1,165 \\
1,212\end{array}$ \\
\hline
\end{tabular}

1 Bands not indicated in Figures 1, 2, 4, or 5 by definite indentation in absorption curve.

The frequencies of the component bands, as given by these equations, ${ }^{18}$ are listed in Table 2. They are also indicated in Figures 1 and 2 by dash-dot ordinates, from which the degree of agreement with the experimental data may be adjudged.

The provisional structures which are thus assigned to the absorption spectra of carotin and xanthophyll are most clearly represented by the schematic diagrams in Figure 3. For comparison, a similar diagram for the absorption spectrum of lycopin (an isomer of carotin), dissolved in methyl-cyclohexane, is also presented in the figure. The data are taken from the work of Pummerer, Rebmann, and Reindel. ${ }^{19}$

The general form of the absorption curve for lycopin is very similar to that for carotin. The entire spectrum is shifted, however, toward the lower frequencies, and an additional absorption region is observed in the far ultra-violet. Four components of the strong band group in the visible spectrum are indicated by the form of the absorption curve, but the curve in the ultra-violet is not determined with sufficient precision to reveal any details of a finer structure.

In explanation of the spectral diagrams we may recall a well-known experimental fact that the frequencies of the lines in atomic and molecular absorption or emission spectra may always be represented as differences between sets of frequencies which are known as spectral terms. The horizontal lines in the spectral diagrams represent the terms for the absorption spectra of these pigments. Differences

18 The half-integral values for $n-n_{\bullet}$ follow directly from the following relation, which is obtained from equation (1) and the absorption curves:

$$
\Delta_{2} / 2 a=(2 q-r)\left(n_{I}-n_{0}\right)+1 / 2\left(2 q^{2}-r^{2}\right)
$$

In deriving this relation let $n_{I}, n_{I}+q$, and $n_{I}+r$ be the values of $n$ for the strongest components of Band Groups I, II, and III, respectively, and $\Delta_{2}$ the second difference between the corresponding frequencies of these three components. $2 a$ is the constant second difference between the frequencies of adjacent component bands. In a preliminary determination of the constants of equation (1) it was noted that the best representation of the experimental data was obtained when the ratio $\Delta_{2} / 2 a$ was approximately zero, for carotin, and approached closely the integral value 36 for xanthophyll. For reasons which will appear later in discussion of Figure 3, the exact ralues 0 and 36 were subsequently imposed on the above ratio, for carotin and xanthophyll, respectively, in a final adjustment of the constants. The imposed condition that $\Delta_{2} / 2 a$ is an integer leads to exact half-integral values for $n-n_{o}$.

19 Ber. d. Deut. Chem. Gesell., 62, p. 1411, 1929. The positions of the bands were estimated from the published absorption curve, and are not known to a degree of accuracy comparable with corresponding data herein presented for carotin and xanthophyll. 
between the terms give the observed frequencies of the absorption bands.

On the basis of the quantum theory of absorption spectra the spectral terms are interpreted as representing different discrete energy states, or energy levels, of the absorption mechanism. Accompanying the absorption of radiant energy of a definite frequency the absorption mechanism may pass from the normal unexcited state (represented by the lower heavy level in the diagram) to one of the higher energy levels. The heavy horizontal lines correspond to component bands of maximum intensity in each group and are used to indicate the energy separation of the groups. They may be designated as group levels in contradistinction to the parabolic set of component

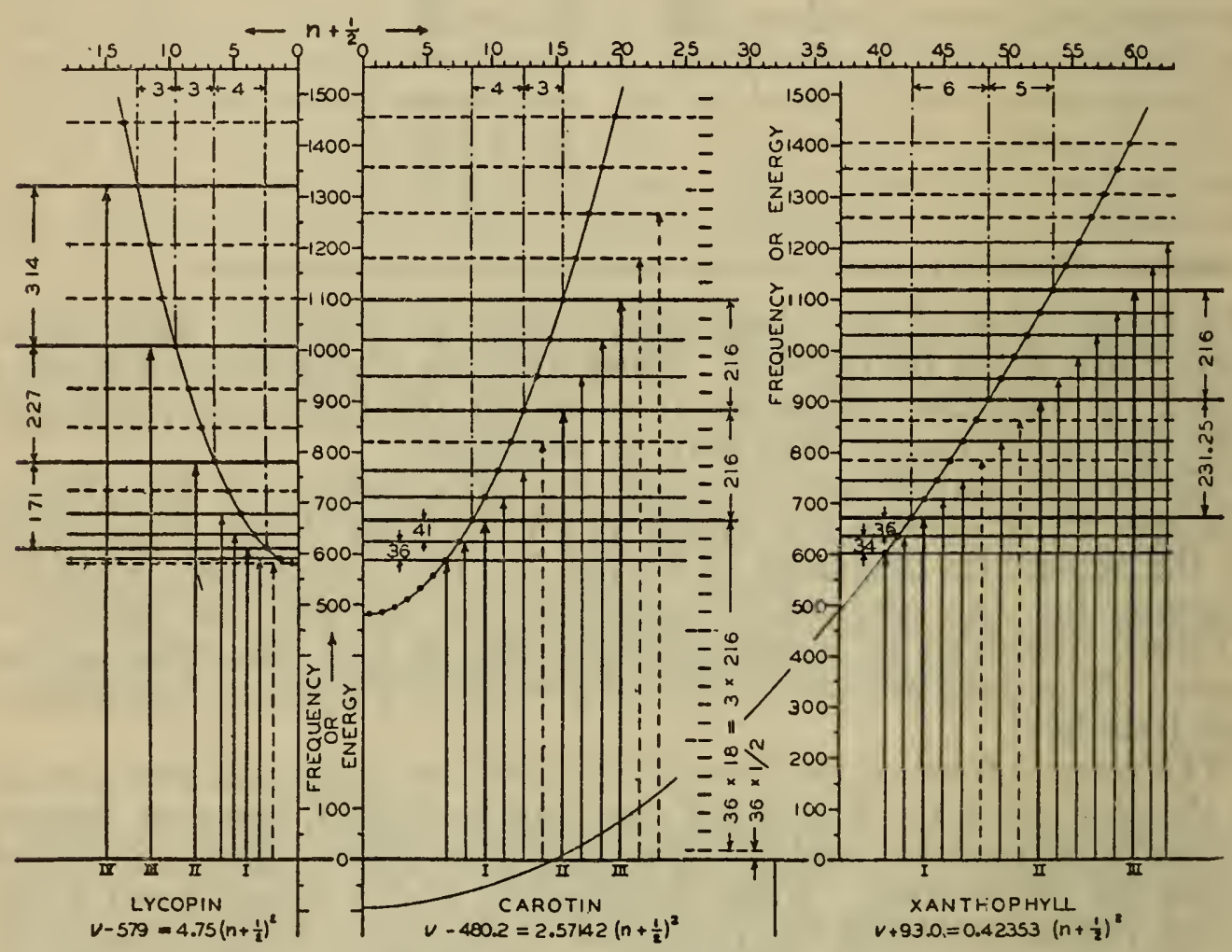

FIGURE 3.- Schematic representation of the absorpiton spectra

band levels. Only levels which are indicated by observed absorption bands are represented by continuous lines. Broken lines show levels suggested by the theoretical scheme.

The absorption spectrum of each pigment is thus represented by a single set of energy levels for the excited states combined with a single energy level for the normal state. The relative intensities of the absorption bands involve the respective probabilities of transitions from the normal to the corresponding excited states. These probabilities must be governed by peculiar conditions which determine the observed variations in intensity.

It is perhaps of further interest to point out certain structural regularities which appear in this schematic representation of the absorption spectra:

1. The observed group-levels for carotin may be equally subdivided and extended to the normal state. The subdivisions of the group 
levels are then represented by the simple formula $\nu_{m}=36\left(m+\frac{1}{2}\right)$, in which $m$ takes successive integral values beginning with zero and the observed group-levels are given by successive values (for $m=3$, $4,5)$ of $6 \mathrm{~m}$. It is quite possible, however, that the indicated relation is an entirely fortuitous numerical combination arising from the circumstance that the frequency 666 of the first band group happens to be divisible by 216 with a remainder of 18 , and the numbers 6,18 , and 36 are each a factor of 216 . If the relation truly follows from some structural condition in the molecule, the spectral arrangement then suggests the possibility that the observed variation in intensity within the sequence of component bands may be related to the periodic coincidence or resonance of two distinct but mutually coupled sets of energy levels in the molecule. In this connection it would be of considerable interest to know if an absorption maximum exists for carotin at a.frequency of 1,458 , for here the two sets of energy levels as depicted in the diagram are again in exact coincidence. No observations have been made in this region of the spectrum, mainly because of the strong absorptive properties of the solvents used. It is observed that lycopin exhibits a region of selective absorption which would correspond to a fourth band group for carotin.

The group levels for lycopin and xanthophyll are not equally spaced and the number of observed levels is not sufficient to determine any regularity which might exist corresponding to the possibility suggested for carotin. A special attempt was made to find a region of selective absorption for xanthophyll in the frequency range from 430 to 250 (wave length 700 to 1,200 millimicrons.) For this experiment a nearly saturated solution in the alcohol-ether solvent was measured in a thickness of $10 \mathrm{~cm}$ using a sensitive thermoelectric method..$^{20}$ No trace of a band was found. It is obviously of considerable importance to extend the work on the absorptive properties of these pigments farther into the higher frequencies.

2. Another point of interest is the occurrence of multiples or submultiples of 36 in the frequency relations. This is particularly marked in the spectrum of carotin, but in the spectra of both pigments the sequence of component bands does not begin on the low frequency side until the frequency separation of the component-band levels is approximately 36. Again (see footnote, 18), the second difference between the frequencies of the three observed group levels in xanthophyll is $36 a$, or eighteen times the constant second difference (2a) between the frequencies of adjacent component bands. The frequency interval of 36 units corresponds to a definite energy unit which may be of some special significance in the theory of these spectra.

3. The direction of convergence of the group levels changes progressively in passing from lycopin ${ }^{21}$ through carotin to xanthophyll. For lycopin the convergence is toward the lower frequencies, for xanthophyll the direction of convergence is reversed, whereas for carotin the group levels appear to be equally spaced.

20 Gibson, J. Opt. Soc. and Rev. Sci. Inst., 7, p. 693; 1923.

21 In making comparisons of the three spectra in Figure 3 it must be borne in mind that lycopin was studied at a concentration and in a solvent both different from the concentration and solvent used for carotin and xanthophyll. Hence, the environmental conditions of the absorption mechanism were not comparable for the three pigment molecules. 
4. The rapidity of convergence of the component band levels, and the value of the constant $a$, both increase progressively with the shift of the vertex $\nu_{0}$ toward the higher frequencies.

5 . The value of the constant $a$ for carotin is approximately six times its value for xanthophyll.

In consideration of these results it should be borne in mind that the definition of the absorption bands, and the extensiveness and accuracy of the experimental data, are such that the indicated structure of the absorption spectra is not established with a high degree of certainty. It is possible that the suggested numerical relations are entirely fortuitous. It may be recalled that the entire scheme is based on the assumption that the poorly defined and partly resolved component bands between the three maximum ordinates of the absorption curve are closely related to one another through the absorption mechanism and form a regular sequence extending throughout the spectrum. The procedure then was to assume the simplest law which would represent this sequence within the limits of uncertainty of the measurements. It is urgently recommended that these observations and speculations be confirmed and tested by further and more extensive studies of the absorptive properties of these pigments. If the numerical relations truly represent some structural conditions in the molecule they may be expected to hold also, with appropriate changes in the constants, at different temperatures and in different solvents or for other changes in the environmental conditions of the molecule. One may ask if the alterations in spectral structure brought about by different solvents or at different temperatures can be represented by corresponding shifts in the origin of the band series, by changes in the relative intensities of the component bands, or by changes in value of $a$. Being no longer in a position to carry on this work the author herein presents such observations and discussion as would seem to be of interest to others in the further study of these molecular spectra.

The molecular spectra of these yellow pigments, and the spectra of other chloroplast and related pigments, offer an interesting field for further investigation, not only from the viewpoint of the biologist, but also as a problem in absorption theory. Further studies may well include extensive measurements of other optical properties, such as rotatory power and fluorescence. Some chemical properties of considerable interest in this connection will be discussed in the Sections $\mathrm{V}$ and VI. Xanthophyll is known to have a high specific rotation. Conflicting reports on the rotation of carotin are found in the literature. Both pigments are fluorescent with a greenish hue, as would be expected if the fluorescence spectra are interpreted as emission spectra accompanying the return of the absorption mechanism from the excited energy states to the normal unexcited state. The absorption and fluorescence spectra may, perhaps, be recorded with greater precision if observations are made at very low temperatures. Under this condition it is known that the broad and apparently continuous absorption and fluorescence bands are often resolved into separate components. In the case of carotin, xanthophyll, lycopin, and other pigments (as shown by the spectograms of Willstatter), the broad absorption bands are already partly resolved at ordinary temperatures. At very low temperatures, therefore, a further resolution may be 
expected so that the relative positions of the bands and the finer structure of the spectra could be observed with greater precision.

\section{OXIDATION IN SOLUTION}

\section{EXPERIMENTAL DATA}

An inspection of the curves in Figures 4 and 5 shows the same sequence of changes in the absorption spectrum of each pigment dur-
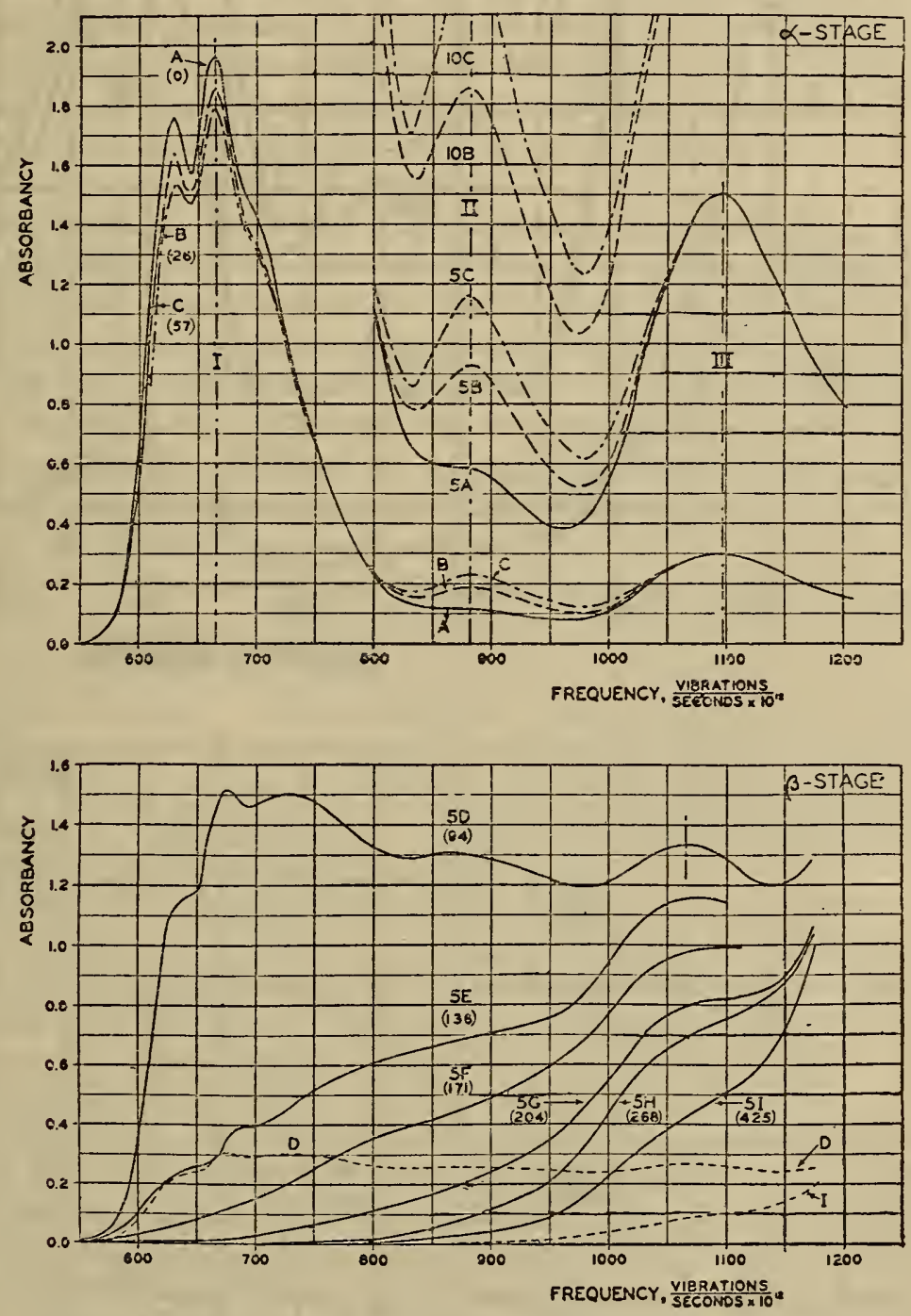

FIGURE 4.-Changes in carotin spectrum, accompanying oxidation

Upper set of curves shows $\alpha$-stage; lower set shows $\beta$-stage. Curve $A$ (upper) represents spectrum of pure unoxidized pigment, as reproduced from Figure 1. These measurements were made on March 10,1922. Curves $B$ to $I$ show changes after successive periods of exposure to oxidizing agencies. Numbers in parentheses give total exposure time in days. Numbers 5 and 10 preceding letters on curves are values of $b c$ used in the experimental determinations (see fig. 1), and (by Beer's law) are also multipliers of corresponding curves of the set $A$ to $I$ (for $b c=1$ ).

ing the slow auto-oxidation process in solution. The rapid development in the intensity of Band Group II is particularly noteworthy in each case. This change is accompanied by a decrease in the intensity of Group I, the rate of change being somewhat greater for the components of lower frequency. This apparent shift in the relative 
intensities of the overlapping components may be partly the result, however, of a broadening of each component. Group III is practi-
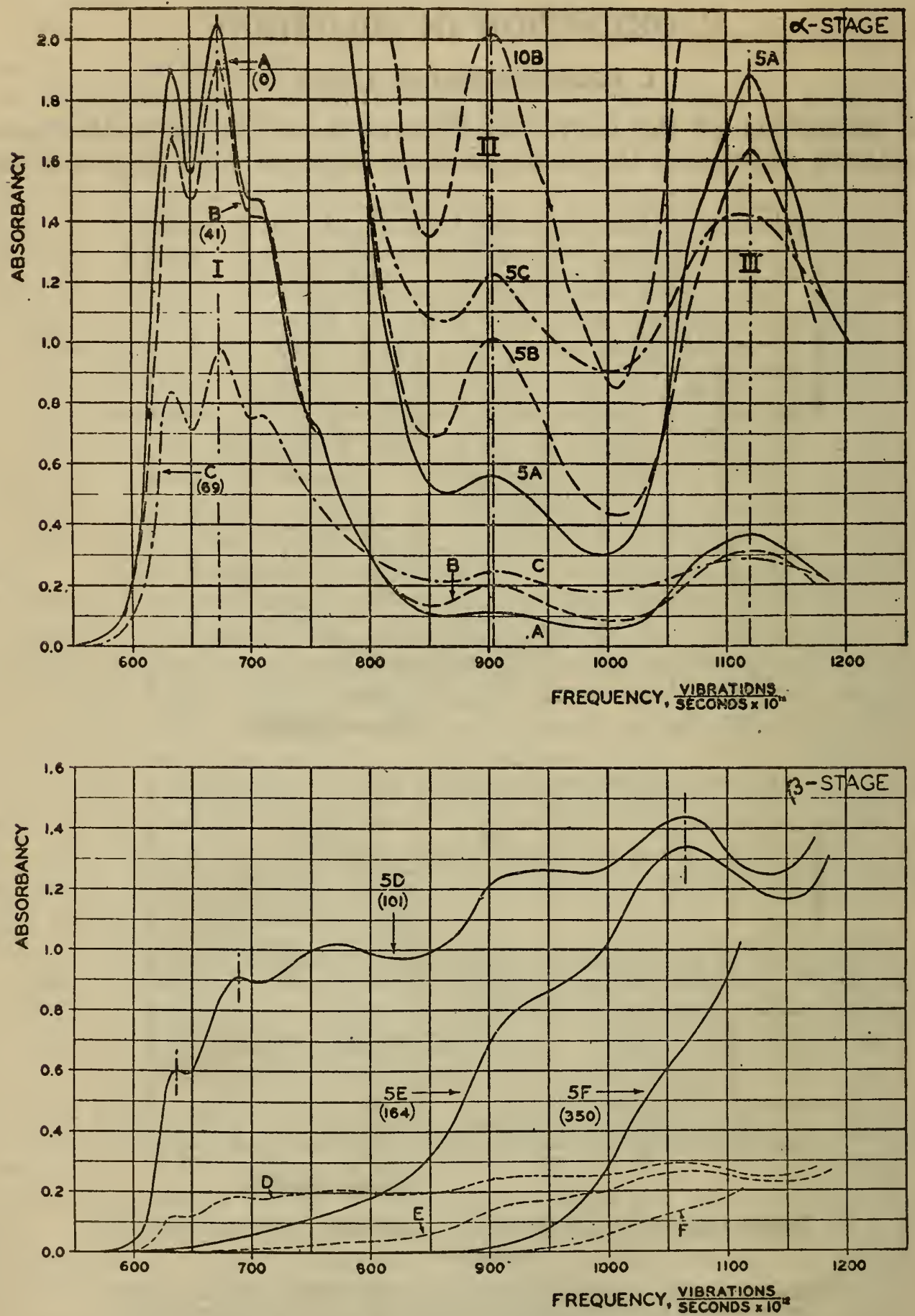

FIGURE 5.-Changes in xanthophyll spectrum, accompanying oxidation

Upper set of curves shows $\alpha$-stage; lower set shows $\beta$-stage. Curve $A$ (upper) represents spectrum of pure unoxidized pigment, as reproduced from Figure 2. These measurements were made on July $21,1922$. Curves $B$ to $F$ show changes after successive periods of exposure to oxidizing agencies. Numbers in parentheses give total exposure time in days. Numbers 5 and 10 preceding letters on curves are values of $b c$ used in the experimental determinations (see fig. 2), and (by Beer's law) are also multipliers of corresponding curves of the set $A$ to $F$ (for $b c=1$ ).

cally unchanged for carotin, but decreases perceptibly in intensity for xanthophyll.

These changes progressed gradually for each of the pigments until some time after the second month of exposure to the oxidizing agencies. 
Then a relatively rapid change took place, the original characteristic bands of the pure pigments fading rapidly with perhaps a simultaneous broadening of the components. The apparent shift of the intensity maximum of Group III toward the lower frequencies is noticed, until it appears centered at a frequency of 1,065 for each pigment.

Further changes in the absorption curves now progress more slowly, with a gradual disappearance of all indications of the original bands.

It may be emphasized that the sequence of these changes with time followed roughly the same course for each pigment, even though the corresponding exposure periods were not simultaneous but occurred during different months of the year. It is highly improbable, therefore, that the rapid change which occurred, following the first slow change, could be ascribed to a sudden increase in the oxidizing agencies acting on either pigment.

The experimental data indicate two very distinct stages in the oxidation process, which are common to both pigments, and are hereafter denoted as the $\alpha$-stage and $\beta$-stage, respectively.

The $\alpha$-stage corresponds to the maximum development of Band Group II in the mid-ultra-violet, with no perceptible shift in the position of any of the absorption bands, as observed for the pure unoxidized material. There is a notable change, however, in the absolute and relative intensities of the components in other groups, particularly in Group I.

The $\beta$-stage in the oxidation process corresponds to the rapid disappearance of all the characteristic bands of the pure material. This is particularly noted in Band Group I, whereas the other groups decrease more slowly. The suddenness with which this change takes place and the marked alteration in the form of the curves suggests that in the $\beta$-stage oxygen is taken up by the molecule in a manner different than in the $\alpha$-stage. Different parts of the molecule are probably involved separately in each stage.

The quantity of oxygen which may be taken up by each pigment molecule is apparently not accurately known, but various statements in the literature indicate that from 10 to 15 atoms are added. Thus, Willstatter ${ }^{22}$ states that carotin bleaches when exposed to dry air, with an increase in weight of from 35 to 41 per cent. These percentages correspond to the addition of 11 or 12 atoms of oxygen.

Although the oxidation was allowed to progress very slowly, molecules in various stages or substages of this process probably were present in the solution when the different determinations of the absorption curve were made. The observations, of course, represent the average effect of all the molecules. The process was slow enough, however, to detect the two main stages described above. Other less definite stages may possibly exist with less characteristic differences in the corresponding absorption curves, so that they would not be clearly indicated in the present experimental work. With a better control of the oxidation process, and more frequent observations of the spectral changes, the existence of other stages might be detected. In the case of xanthophyll a measurement was made fortunately during the period of most rapid change in its absorption curve, after the $\beta$-stage was well under way. (Curve C, fig. 5.) The rapid fading of Band Group I is clearly observed. Group II has passed its maximum development and is also fading rapidly. The broadening and initial

22 Investigations on chlorophyll, English translation, p. 219. 
shifting of Group III to lower frequencies is evident. In the case of carotin this change had progressed even further before a measurement was made. Because of the similarity in the sequence of changes for each pigment, the entire set of curves in Figures 4 and 5 may be taken to illustrate the progressive changes occurring during the oxidation of either pigment.

Although xanthophyll has been regarded by some investigators as simply a stage in the oxidation of carotin, it is evident from the data herein presented that carotin is not converted into xanthophyll by the simple auto-oxidation process. The carotin spectrum never goes over into that of xanthophyll; on the other hand, both spectra pass through the same series of changes until oxidation is complete.

\section{TEST FOR OXIDATION}

The marked development of Band Group II during the early stage of the oxidation process, suggests the possibility that the original solutions, though freshly and carefully prepared, were nevertheless in a slightly oxidized condition, and that solutions of pure unoxidized carotin and xanthophyll might show no indication of the bands in question.

To test this hypothesis, fresh crystals of each pigment were prepared ${ }^{23}$ by repeated crystallization. The crystals finally obtained were not dried and weighed, as in the previous preparations, but the possibility of oxidation during this operation was avoided by immediately dissolving the crystals in pure ethyl alcohol and diluting with alcohol to a concentration which was determined by rough trial to be suitable for the test.

The absorption measurements were made without delay, but no reduction in the relative intensity of Band Group II was observed for either pigment, beyond that shown in Figures 1 and 2. It appears, therefore, that this band group is characteristic of each pure unoxidized pigment, but develops rapidly in intensity during the earliest stage of oxidation. The extent to which this band group is developed thus provides a sensitive test for incipient oxidation.

\section{BEARING OF THE OXIDATION EXPERIMENTS ON THE WORK OF OTHER INVESTIGATORS}

The oxidation experiments herein described have an important bearing on some previous work of Tswett, ${ }^{24}$ who obtained by means of his chromatographic adsorption analysis a separation of different materials present in an extract from green leaves. The principle of the method lies in the phenomenon of surface adsorption, which is manifested to a marked degree when a solution containing the mixture of pigments is passed through a column of a suitable finely divided adsorbing material. The pigments are adsorbed on the surfaces of the particles, and may mutually displace each other in accordance with their adsorption "affinity" for the adsorber. Tswett used a column of finely divided calcium carbonate packed in a vertical glass tube. Upon passing a carbon disulphide solution of the pigments

${ }_{23}$ These preparations were made by Doctor Schertz, using the inethods described in his papers, as previously cited. (See footnote 5, p. 172.)

24 Ber. der Deut. Bot. Ges., 24, pp. 316, 384; 1906. See Also Palmer, Carotinoids and Related Pigments, p. 43 . 
slowly through this column from top to bottom, there appeared a stratification of the material into separate colored zones, each zone corresponding to a different pigment ingredient of the mixture. The zones could then be mechanically separated and the individual pigments extracted with suitable solvents.

By this method Tswett separated five yellow pigments (among other green chloroplast pigments) one of which he identified as carotin and the other four were distinguished as $\alpha, \alpha^{\prime}, \alpha^{\prime \prime}$, and $\beta$ xanthophylls. The order of increasing adsorption affinity for calcium carbonate was from xanthophyll $\beta$ through the $\alpha^{\prime \prime}, \alpha^{\prime}$, and $\alpha$ forms to carotin, which is only slightily adsorbed. Xanthophyll $\alpha$ was orange-yellow in color and showed, by the spectrogram method, spectral absorption bands in alcoholic solution corresponding closely in position to the bands of pure xanthophyll, as herein exhibited in Figure 2. The $\alpha^{\prime}$ and $\alpha^{\prime \prime}$ xanthophylls were first formed in a single yellow zone which separated into a double zone when benzene was passed through the tube. They are only slightly different in their adsorption affinity for the carbonate. The positions of the absorption bands were the same for each material, but were reported by Tswett to be shifted slightly toward the ultra-violet as compared with the bands for xanthophyll $\alpha$. Only the stronger components of Band Group I were recorded. Xanthophyll $\beta$ showed more characteristic differences in its properties, as compared with the other xanthophylls. The two principal components of Group I were shifted very perceptibly toward the ultra-violet and located, respectively, in the frequency ranges 632 to 650 and 674 to 698 .

An examination of the curves in Figure 5 provides a plausible and complete explanation of Tswett's observations and strongly suggests that the different xanthophylls described are but separate stages in the oxidation of this pigment, with xanthophyll $\alpha$ corresponding to the pure unoxidized material.

Thus, it may be noted that in the $\alpha$-stage of oxidation there.is a small but definite broadening of the components of Group I, particularly on the ultra-violet side. This change undoubtedly would be o bserved by the spectrogram method as a slight shift in the positions of the centers of the components. It may be presumed, therefore, that the $\alpha^{\prime}$ and $\alpha^{\prime \prime}$ modifications of xanthophyll both correspond to the $\alpha$-stage of oxidation, as defined in the preceding section, but indicate however the existence of two definite substages in this process. Although the absorption curves herein presented do not show these two substages, they may well exist with nearly identical absorption spectra, but with definite differences in their adsorption affinity for calcium carbonate. It is unfortunate that the ultra-violet bands were not recorded, for the marked increase in the intensity of Group II in the mid-ultra-violet is a definite criterion for oxidation.

The marked change in the absorption spectrum during the $\beta$-stage of oxidation, undoubtedly corresponds to the formation of 'Tswett's xanthophyll $\beta$. As observed by the spectrogram method, the positions of the broadened and rapidly disappearing components of Group I, now centered at frequencies of 637 and 690 (fig. 5 , curve $5 D$ ), would appear more definitely shifted toward the higher frequencies than in the earlier stage of oxidation.

The $\alpha$ xanthophylls were found to predominate in the adsorption column whereas xanthophyll $\beta$ formed only a relatively narrow zone. 
It seems very probable indeed that Tswett was dealing, for the most part, with partially oxidized materials.

This conclusion is in accord with some more recent experiments of Schertz, ${ }^{25}$ who found that when a carbon disulphide solution of carefully purified xanthophyll is passed through a column of calcium carbonate, the pigment is only slightly adsorbed. If the solution which has passed through the adsorption column is now exposed to air and light, a greater portion of the pigment will then be retained by the carbonate. Usually the longer the solution is exposed to the oxidizing agencies the greater the quantity of the pigment retained. Carotin behaved in approximately the same way. . Solutions of pure carotin in carbon disulphide left only a trace of the yellow pigment in the adsorption column, whereas solutions of partially oxidized material left a definite colored zone. The effect was always greater with xanthophyll.

Although the data herein reported show the same oxidation stages for both pigments, the lower adsorption affinity of carotin for calcium carbonate may well account for the failure of previous investigators to detect the corresponding oxidation stages for this pigment.

The possibility that oxidation might account for the observations of Tswett was indeed suggested by Willstatter, ${ }^{26}$ on the basis that the pigment, when in the adsorbed condition, would be particularly susceptible to oxidation. Furthermore, the possiblity was not excluded by Willstatter that xanthophyll, as abstracted from the other chloroplast pigments, might consist of several very similar isomeric bodies - not easily detected or separated by the usual chemical methods.

In this connection some recent observations by Zechmeister and Tuzson ${ }^{27}$ are of interest. These investigators found considerable divergence in the specific optical rotation of different preparations of xanthophyll and suggested as a possible explanation of these observations that the leaf extracts of xanthophyll might consist of very similar components with unequal specific rotation. These variations in the optical rotatory power of different preparations of presumably pure unoxidized xanthophyll recall somewhat analogous variations observed by the author in the relative intensity of Band Group II for some early preliminary preparations of these pigments. It would seem a pertinent question for further investigation whether different isomorphic forms of xanthophyll really exist, with slightly different optical properties, or whether the observed variations in specific rotation are again another manifestation of varying degrees of partial oxidation in the different preparations of the pigment. Considerable care is required in the preparation and handling of these pigments to avoid incipient oxidation.

The changes in the absorption spectrum, accompanying oxidation, also bear a direct relationship to the work of Zechmeister and his associates ${ }^{28}$ on the progressive hydrogenation of carotin and xanthophyll. 'These investigators observed two definite stages in the hydrogenation of each pigment, each stage being attributed to the saturation of a different group of double bonds in the molecule. During the first stage of the process 18 atoms of hydrogen are taken up with the saturation of 9 double bonds and complete disappearance of the

25 Plant Physiology, 4, p. 337; 1929.

28 Investigations on chlorophyll. English Translation, p. 212.

27 Ber. der Deut. Chem. Ges., 62, p. 2226; 1923.

28 Ber. d. Deut. Chem. Geseli., 61, pp. 566, 1534, 2003; 1928: 62, pp. 2226, 2233; 1929. 
color of the solution. The color fades continuously with increasing consumption of hydrogen. During the second and final stage of the hydrogenation process four additional atoms of hydrogen are taken up with the saturation of a different and more stable group of two double bonds. The first group of nine double bonds is assumed to form a conjugated system and is responsible for the strong absorptive properties of the molecule. Quantitative spectrophotometric measurements were not made of the progressive changes in the absorption spectrum during hydrogenation.

It has been shown that in the $\alpha$-stage of the oxidation process the characteristic absorption spectrum of the molecule was not destroyed, there being moderate changes only in the relative intensities of the component bands. As the changes which occurred in the visible spectrum were small, the color of the solution remained nearly constant. It was during the $\beta$-stage that the color faded rapidly as a result of the sudden decrease in the intensity of the low-frequency components of Band Group I in the visible spectrum. In the hydrogenation process the opposite effect was observed, the color disappearing completely during the first stage of this process. In accordance with present chemical evidence it appears likely that during the oxidation process at least 11 atoms of oxygen are taken up by a molecule of carotin or xanthophyll. This quantity of oxygen is equivalent in primary valencies to the 22 atoms of hydrogen consumed in the hydrogenation process. In both chemical processes the changes in the absorption spectra are intimately related to the gradual saturation of the system of conjugated double bonds. In the oxidation process it appears that the $\alpha$-stage corresponds to the saturation of the second group of noncolor producing bonds, this change being followed by the saturation of the first, or conjugated, group. In the hydrogenation process the saturation occurs in reverse order. On the basis of these observations it seems plausible to suggest that in the saturation of the 11 double bonds 2 atoms of oxygen are taken up during the $\alpha$-stage and the remaining 9 atoms during the $\beta$-stage.

\section{CONCLUDING REMARKS}

The present status of investigations on the molecular structure of carotin and xanthophyll is summarized in recent papers by Smith, ${ }^{29}$ Gulland, ${ }^{30}$ and by Karrer ${ }^{31}$ and his associates. Carotin is conceived as an acyclic chain of four isoprene residues with two identical, or very similar, carbocyclic ring structures, one at each end of the chain. The entire atomic configuration is very symmetrical. The nine conjugated double bonds are in the isoprene chain and one (probably) nonconjugated double bond is located in each of the end rings. All investigators are not in complete agreement, however. on some details of this structure. The structure of xanthophyll is likewise not definitely determined. The position and function of the two oxygen atoms in the empirical formula for this molecule is not fixed, but chemical evidence points to their location in the end ring structures. In view of the similarity in physical and chemical properties of these

${ }^{29}$ Contributions to Marine Biology, Stanford University Press, p. 145; Sept. 1, 1930.

$30 \mathrm{~J}$. Sec. Chem. Ind. (Transactions and Abstracts), 49, p. 839; 1930.

31 Helv. Chim. Acta., 13, p. 1084; 1930.

$60869-31-13$ 
pigments there can be little doubt that their molecules are constructed on essentially the same atomic pattern.

On the basis of this provisional picture of molecular structure we may explain the observation of two substages in the a-stage of oxidation as corresponding each to the saturation of one of the two double bonds in the end rings. It may be recalled that these two substages for xanthophyll were suggested by the interpretation herein applied to Tswett's chromatographic analysis. The $\beta$-stage of oxidation for each pigment may be ascribed to the progressive saturation of double bonds in the open chain structure of each molecule.

It is conceivable that the a-stage of oxidation may be reversible under proper conditions in the plant, so that these pigment molecules, whether existing independently as such in the plant cell or as part of a more complex atomic assemblage, may serve as an oxidationreduction system concerned with the transference of oxygen. It has been shown that in the $a$-stage the strong absorptive properties of the molecule were practically unimpaired; so that the reversible changes in state of the molecule, accompanying the absorption and reemission of radiant energy, may be available to bring about, or assist in some unknown manner, the suggested oxidation-reduction reactions.

Further studies of the oxidation and reduction processes will undoubtedly contribute materially to our knowledge of the structure and possible functions of these pigments. The pigments in different stages of the processes should be isolated if possible, and their spectral absorptive properties determined quantitatively along with the quantity of oxygen or hydrogen taken up. The results obtained thus far are duly reflected in the suggested molecular structures of these pigments, and have, furthermore, yielded pertinent information on the carrier of the observed system of absorption bands. Thus it appears that the absorption mechanism is most closely allied with the system of conjugated double bonds.

The present status of our knowledge of the absorption process in these large and complex atomic systems is far too meager, of course, to warrant any definite conclusions therefrom concerning the origin of the spectra or the structure of the molecule. It is probable that the absorption process giving rise to the visible and ultra-violet spectrum can not be localized entirely within a pair or small group of atoms with their associated electronic binding system, or referred even to a spacial arrangement of identical or very similar small and independently acting absorption units; on the other hand, the absorption process more likely is concerned principally with the mutually interaction of the many valence electrons forming the binding system in the entire chain structure of the molecule. The manifold possibilities in the configurations or motions of this constellation of electrons may give rise to a very complex arrangement of energy states only the grossest features of which would be represented in Figure 3. The constraining and disturbing influence of the complex environmental conditions of the absorption mechanism probably hides a much finer basic arrangement of energy levels. We would expect that any structural changes in the end rings of the molecule, as accompanying the a stage of oxidation or the structural transition from carotin to xanthophyll, would exert a definite influence on the energy levels and thus bring about corresponding changes in the spectrum. The close simple relation which appears to exist between all the observed absorp- 
tion bands indicates that they must all be referred to one absorption mechanism; and it would seem to be at least a plausible hypothesis that all essential parts of the molecular structure are more or less directly concerned in the absorption process.

In conclusion, it may not be amiss to point out certain experimental deficiencies in the various investigations as described in the preceding two sections. In the earlier work on the identification and classification of the chloroplast pigments, much labor and controversial discussion would undoubtedly have been avoided if the chemical investigations had been supplemented by thorough quantitative records of the absorption spectrum over a sufficiently wide range of spectral frequencies. In the present spectrophotometric study of the oxidation process no chemical determinations were made of the quantity of oxygen taken up. Furthermore, data on the optical rotatory power and its variations with oxidation would prove very valuable in connection with the observations of Zechmeister and Tuzson. In the hydrogenation experiments, on the other hand, quantitative spectrophotometric studies of the changes in the absorption spectra were not made and incomplete rotation data were obtained. In each case the additional physical or chemical data would be of great value in the interpretation of the results. These investigations, then, may collectively serve to illustrate the decided advantages which would certainly accrue from a greater organized effort on the part of both physicists and chemists to collaborate in applying the apparatus and methods of their respective sciences in the study of these biological problems.

Washington, April 10, 1931. 